\title{
Thermochemistry of Eight Membered Ring Hydrocarbons. The Enthalpy of Formation of Cyclooctane
}

\author{
DANIELA GHEORGHE ${ }^{1 *}$, ANA NEACSU ${ }^{1}$, STEFAN PERISANU $^{2}$ \\ ${ }^{1}$ Ilie Murgulescu Institute of Physical Chemistry of the Romanian Academy, 202 Splaiul Independentei, 060021, \\ Bucharest, Romania \\ ${ }^{2}$ Politehnica University of Bucharest, Department of General Chemistry, 1 Polizu Str., 011061, Bucharest, Romania
}

\begin{abstract}
A new value of the enthalpy of formation of cyclooctane $\left(-156.2 \pm 1.2 \mathrm{~kJ} \mathrm{~mol}^{-1}\right)$ based on heat of combustion measurements is reported. Its solid - liquid phase change was investigated by differential scanning calorimetry in both directions revealing an overcooling effect of over $23 \mathrm{~K}$. Our enthalpy of formation of cyclooctane was used together with literature values of heats of hydrogenation of 8 carbon atoms cycloolefins to calculate the enthalpies of formation of the later. The strain energies of the investigated molecules were calculated and discussed.
\end{abstract}

Keywords: cyclooctane; enthalpy of formation; strain energies; differential scanning calorimetry (DSC); overcooling.

\section{Introduction}

The literature value for the enthalpy of formation of cyclooctane, selected and reanalyzed by Cox and Pilcher [1] (i.e. $\Delta_{f} H^{\mathbf{o}}$ liq $=-169.4 \pm 1.6 \mathrm{~kJ} \mathrm{~mol}^{-1}$ ) is based on the enthalpy of combustion measured by Spitzer and Huffman in 1947 [2] $\left(\Delta_{c} H^{\circ}\right.$ liq $\left.=-5265.7 \pm 0.9 \mathrm{~kJ} \mathrm{~mol}^{-1}\right)$. A relatively more recent determination comes from Kaarsemaker and Coops [3] in 1952 whose value yields $\Delta_{f} H^{\mathbf{o}}{ }_{\text {liq }}=-169.0 \mathrm{~kJ}$ $\mathrm{mol}^{-1}$. The values from both references agree within the error limits as well as with that from DIPPR 801 project [4] (-167.74 $\left.\mathrm{kJ} \mathrm{mol}^{-1}\right)$. An even older value of the enthalpy of combustion was reported by Ruzieka and Schlapfer in 1933 for the solid state [5]. Their value was used by NIST [6] to obtain $\Delta_{f} H^{\mathbf{o}}$ solid $=-182 \mathrm{~kJ} \mathrm{~mol}^{-1}$. Enthalpies of formation of unstrained alkanes were calculated by Zavitsas et al. [7, 8] based on the number of different kinds of hydrogen atoms. The enthalpy of formation of cyclooctane is not important only for the study of the energetics of this molecule, but also of that of all eight membered ring cycloalkenes, whose enthalpies of formation are derived from enthalpies of hydrogenation to cyclooctane.

\section{Materials and methods}

\subsection{Materials}

The cyclooctane used was a product of Aldrich (CAS No. 292-64-8, purity >99\%). The liquid samples were dried and stored over $4 \AA$ molecular sieves and used without further purification. Evidence of chemical purity is also provided by comparison of measured physical properties, which are in good agreement with literature values, as it can be seen in Table 1. The molecular weights of the compounds were calculated using values recommended by the IUPAC Commission, in 2011 [9], for the atomic weights of their constituent chemical elements.

\section{Apparatus and experimental procedures \\ Refractive indices and density}

Measurements of the refractive index of cyclooctane were carried out at sodium D-line, $\lambda_{\mathrm{D}}=589.3$ $\mathrm{nm}$, using a digital automatic refractometer (Anton Paar RXA 170) with an accuracy of $\pm 0.01 \mathrm{~K}$ in temperature and of \pm 0.000001 for refractive index.

\footnotetext{
*email:gheorghedanny2@gmail.com
} 
The density measurements at $298.15 \mathrm{~K}$ for cyclooctane were carried out by using a density and sound velocity meter Anton Paar DSA-5000 M with an accuracy of $\pm 0.05 \mathrm{~kg} \mathrm{~m}^{-3}$. Dried air and deionized ultra-pure water at atmospheric pressure were used as calibration fluids. The sample temperature was maintained constant within $\pm 0.01 \mathrm{~K}$. The experimental data for refractive index and density at $T=298.15 \mathrm{~K}$ are shown in Table 1.

Table 1. Physical properties of cyclooctane at $T=298.15 \mathrm{~K}$ and $P^{\mathrm{o}}=0.1 \mathrm{MPa}$

\begin{tabular}{|c|c|c|}
\hline Properties & $\boldsymbol{n}_{\boldsymbol{D}}^{\mathbf{2 9 8 . 1 5} \mathbf{K}}$ & $\mathbf{1 0}^{\mathbf{- 3}} \cdot \mathbf{\rho} / \mathbf{k g} \cdot \mathbf{m}^{\mathbf{- 3}}$ \\
\hline Experimental & 1.455897 & 0.831546 \\
\hline Literature & $1.45598[10]$ & $0.83147[10]$ \\
\hline
\end{tabular}

\subsubsection{Combustion calorimetry}

A Parr Instruments model 6200 microprocessor controlled isoperibol oxygen bomb calorimeter was used in combustion experiments. Temperature is measured with a high precision electronic thermometer using a specially designed thermistor sensor. Measurements were taken with $0.0001 \mathrm{~K}$ resolution. The jacket temperature is held constant for isoperibol operation. A microprocessor-based controller monitors both the temperatures of the bucket and of the jacket and performs the necessary heat leak corrections that result from differences between these two temperatures. These corrections are applied continuously throughout a test rather than as a final correction based on pre and post test measurements.

The combustion calorimeter was calibrated by means of ten combustion experiments with benzoic acid (CAS 65-85-0) supplied by Parr Company, having the massic energy of combustion under certificate conditions $\left(\Delta_{c} u^{o}=-26434.5 \mathrm{~J} \mathrm{~g}^{-1}\right)$. The energy equivalent of our calorimeter was determined as $\varepsilon_{\text {calor }}=(10054.4 \pm 1.4) \mathrm{J} \mathrm{K}^{-1}$. The uncertainty associated with the average value of the energy equivalent is the standard deviation of mean.

The combustion bomb Parr Instruments standard type 1108 is a cylinder, with an internal volume of about $0.35 \mathrm{~L}$, made of stainless steel, as well as its accessories. The samples burned in the oxygen filled bomb were enclosed in Parr 3601 Gelatin Capsules with maximum $0.9 \mathrm{~mL}$ volume. A cotton thread was used in order to ignite the samples. The completely equipped bomb (filament, fuse, gelatin capsule, sample, deionized water) was connected to the oxygen cylinder and flushed with oxygen. All combustion experiments were carried out in high purity oxygen $99.998 \%$ at $3.546 \mathrm{MPa}$ and at $T=$ $298.15 \mathrm{~K}$ and in the presence of $1 \mathrm{~cm}^{3}$ of deionized water for saturation of the atmosphere.

\subsubsection{Differential scanning calorimetry}

A Perkin Elmer power compensated DSC (model 8500) was used for the measurement of the enthalpies of the processes occurring during temperature scan (fusion and crystallization). The calorimeter was calibrated with high purity indium $\left(T_{\mathrm{m}}=429.75 \mathrm{~K}\right.$ and $\left.\Delta_{\text {fus }} H=28.46 \mathrm{~J} \mathrm{~g}^{-1}\right)$. The areas of the peaks corresponding to the standard and studied samples were used to calibrate the instrument and calculate the thermal effects for cyclooctane. Aluminum sealed pans were used. The DSC experiments were done at a heating rate of $10 \mathrm{~K} \mathrm{~min}^{-1}$ using nitrogen with purity $>99.996 \%$ (flux 20 $\mathrm{mL} \mathrm{min}^{-1}$ ). The heat flow curves were processed by means of Pyris Software, which delivered the thermal effects and the purity.

\section{Results and discussions}

\subsection{Combustion energy}

The data of the combustion measurements for cyclooctane are given in Table 2. Samples amounting between $0.1-0.4 \mathrm{~g}$ and gelatin capsules with a mass of $0.10-0.12 \mathrm{~g}$ were used in each experiment. The samples were weighed with a Mettler-Toledo microbalance with an accuracy of 
$\pm 2 \cdot 10^{-6} \mathrm{~g}$. Some runs were rejected because of doubt about combustion completeness. The corrections for the gelatin capsule, the cotton thread and filament used in the combustion experiments were calculated from the corresponding masses and energies of combustion. $\Delta_{c} u^{\circ}$ (gelatin capsule) $=19294 \pm 3 \mathrm{~J} \mathrm{~g}^{-1}$ was determined in our laboratory (to be compared with the value certified by the fabricant $19.26 \mathrm{~kJ} \mathrm{~g}^{-}$ ${ }^{1}$ ), $\Delta_{c} u^{\circ}$ (cotton) $=16709 \pm 5 \mathrm{~J} \mathrm{~g}^{-1}$ checked in our laboratory in agrrement with literature value $16240 \mathrm{~J} \mathrm{~g}^{-1}$ [12] and $\Delta_{c} u_{(\mathrm{Ni}-\mathrm{Cr})}^{\circ}=5.86 \mathrm{~kJ} \mathrm{~g}^{-1}$ (certified by the calorimeter's fabricant). In order to bring the experimental values of the energy of combustion to the standard state $\left(T=298.15 \mathrm{~K}\right.$ and $P^{\circ}=0.1$ $\mathrm{MPa})$, corrections were made with the Washburn approximate equation [13]:

$$
\Pi \%=\frac{-0.3 \cdot a \cdot P_{\text {initial }}}{-\Delta U^{\exp }}\left[1-\frac{1.1 \cdot(b-2 \cdot c)}{4 \cdot a}+\frac{2}{P_{\text {initial }}}\right]
$$

where: $P$ stands for the initial oxygen pressure and $-\Delta U$ exp for the experimental energy of combustion; $a, b$, and $c$ are the numbers of carbon, hydrogen and oxygen atoms from the chemical formula of the compound, $\mathrm{C}_{a} \mathrm{H}_{b}$. The Washburn correction $\Pi$ is calculated in percents from the experimental value.

Table 2. Results for typical combustion experiments at $T=298.15 \mathrm{~K}$ and $P^{\circ}=0.1 \mathrm{MPa}$ for cyclooctane liquid $*$

\begin{tabular}{|c|c|c|c|c|c|c|c|}
\hline Sample & 1 & 2 & 3 & 4 & 5 & 6 & 7 \\
\hline $\boldsymbol{m}_{\text {sample }} / g$ & 0.340047 & 0.282063 & 0.197046 & 0.213378 & 0.273059 & 0.258980 & 0.207492 \\
\hline$m_{\text {capsule }} / g$ & 0.113303 & 0.115819 & 0.111027 & 0.114851 & 0.113728 & 0.11626 & 0.110691 \\
\hline $\boldsymbol{m}_{(\mathrm{Ni}-\mathrm{Cr})} / \boldsymbol{g}$ & 0.007585 & 0.008269 & 0.000005 & 0.00622 & 0.002811 & 0.00542 & 0.003892 \\
\hline$m_{\text {cotton }} / g$ & 0.009182 & 0.008555 & 0.008589 & 0.007849 & 0.007883 & 0.009052 & 0.010031 \\
\hline$\Delta T / K$ & 1.8267 & 1.5598 & 1.1483 & 1.2345 & 1.5095 & 1.4516 & 1.2009 \\
\hline$\varepsilon_{c a l o r}\left(-\Delta T_{c}\right) / J$ & -18366.36 & -15682.85 & -11545.46 & -12412.15 & -15177.11 & -14594.96 & -12074.32 \\
\hline - $\boldsymbol{m}_{\text {capsule }} \boldsymbol{\Delta}$ cu ${ }^{\circ}{ }_{\text {capsule }} / J$ & -2186.09 & -2234.63 & -2142.18 & -2215.96 & -2194.29 & -2243.14 & -2135.69 \\
\hline$-\boldsymbol{m}_{\text {wire }} \Delta_{c} \boldsymbol{u}^{\circ}{ }_{\text {wire }} / \boldsymbol{J}$ & -44.43 & -48.44 & -0.03 & -36.43 & -16.47 & -31.75 & -22.8 \\
\hline$-m_{\text {cotton }} \Delta_{c} u_{\text {cotton }}^{\circ} / J$ & -153.42 & -142.95 & -143.51 & -131.15 & -131.72 & -151.25 & -167.61 \\
\hline$-\Delta_{c} u / J g^{-1}$ & -47000.6 & -46999.5 & -46992.8 & -46999.3 & -47003.2 & -46987.5 & -46981.2 \\
\hline$-\Delta_{c} u \% J g^{-1}$ & -46958.0 & -46956.9 & -46950.2 & -46956.7 & -46960.6 & -46944.9 & -46938.6 \\
\hline$<\Delta_{c} u 9 / J^{-1}$ & \multicolumn{7}{|c|}{$-(46952.3 \pm 8.1)$} \\
\hline
\end{tabular}

The standard combustion enthalpy $\Delta_{\mathrm{c}} H^{\mathrm{o}}$ of cyclooctane was calculated taking into account the following reaction:

by using the equation:

$$
\mathrm{C}_{8} \mathrm{H}_{16}(\mathrm{l})+12 \mathrm{O}_{2}(\mathrm{~g}) \longrightarrow 8 \mathrm{CO}_{2}(\mathrm{~g})+8 \mathrm{H}_{2} \mathrm{O}(\mathrm{l})
$$

$$
\Delta_{\mathrm{c}} H^{\mathrm{o}}=\Delta_{\mathrm{c}} U^{\mathrm{o}}+\Delta n R T
$$

where $\Delta n$ is the change in the mole number of gaseous compounds during the combustion reaction:

$$
\Delta n=\Sigma n_{\text {products,g }}-\sum n_{\text {reactants,g }}
$$

As recommended by Olofsson [14], the uncertainty associated with the molar enthalpy of combustion is twice the overall standard deviation of the mean, and it includes the uncertainties 
associated with the calibration experiments (uncertainties of massic energy of combustion of benzoic acid and energetic equivalent of the calorimeter) and with the auxiliary materials.

The following values were considered: $\Delta_{\mathrm{f}} H_{\mathrm{CO}(\mathrm{g})}^{\mathrm{o}}=-393.51 \pm 0.13 \mathrm{~kJ} \mathrm{~mol}^{-1}, \Delta_{\mathrm{f}} H_{\mathrm{H} 2 \mathrm{O}(\mathrm{l})}^{\mathrm{o}}=-$ $285.83 \pm 0.042 \mathrm{~kJ} \mathrm{~mol}^{-1}$ [15] for calculating the enthalpy of formation,. The obtained value of the standard molar enthalpy of formation in liquid-state is shown in Table 3 , together with literature [1, 4, 6] and calculated values [16].

Table 3. Thermochemical data at $T=298.15 \mathrm{~K}$ and $P^{\circ}=0.1 \mathrm{MPa}$ for liquid cyclooctane

\begin{tabular}{|c|c|c|c|c|}
\hline$-\Delta_{\mathrm{c}} U^{\mathrm{o}} / \mathbf{k J} \mathrm{mol}^{-1}$ & $-\Delta_{\mathrm{c}} H^{\mathrm{o}} / \mathrm{kJ} \mathrm{mol}^{-1}$ & $\begin{array}{c}-\Delta_{\mathrm{f}} H^{\mathrm{o}} / \mathrm{kJ} \mathrm{mol}^{-1} \\
\text { (this work)* }^{-1}\end{array}$ & $\begin{array}{c}-\Delta_{\mathrm{f}} H^{\mathrm{o}} / \mathbf{k J} \mathrm{mol}^{-1} \\
\text { (literature) }\end{array}$ & $\begin{array}{c}-\Delta_{\mathrm{f}} H^{\mathrm{o}} / \mathbf{k J} \mathrm{mol}^{-1} \\
\text { (calculated) }\end{array}$ \\
\hline $5268.5 \pm 1.1$ & $5278.4 \pm 1.1$ & $156.2 \pm 1.2$ & $\begin{array}{c}169.4 \pm 1.6[1] \\
169.0 \text { (no Washburn corrections) [3] } \\
167.74[4] \\
\end{array}$ & $\begin{array}{l}205.84 \text { [16] } \\
\text { (strainless) }\end{array}$ \\
\hline
\end{tabular}

*Uncertainty is standard deviations and includes the uncertainties of the enthalpies of formation of the reaction products $\mathrm{H}_{2} \mathrm{O}$ and $\mathrm{CO}_{2}$.

\subsection{DSC runs}

The purity of liquid cyclooctane could be estimated from the DSC curve, based on the shape and the temperature of the DSC melting endotherm, as is shown in Figure. 1.

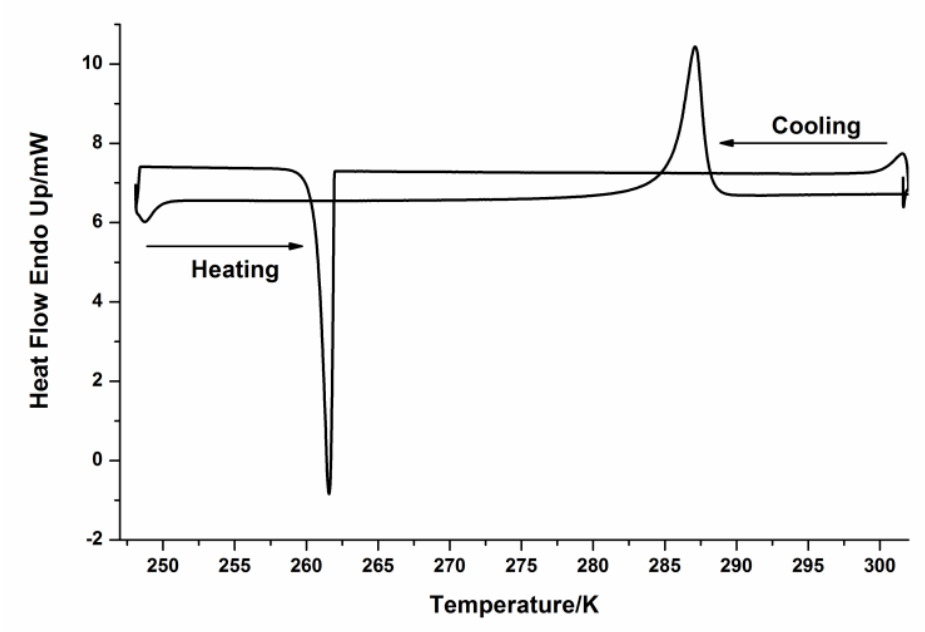

Figure 1. DSC curve of cyclooctane

Table 4. Thermochemical parameters of cyclooctane derived from DSC measurements

\begin{tabular}{|c|c|c|c|c|}
\hline Process & $\boldsymbol{T}_{\mathbf{o n} \text { set }} / \mathbf{K}$ & $\boldsymbol{T}_{\mathbf{m a x}} / \mathbf{K}$ & $\boldsymbol{T}_{\text {end set }} / \mathbf{K}$ & $\Delta \boldsymbol{H}_{\text {Process }} / \mathbf{k J} \mathbf{~ m o l}^{-\mathbf{1}}$ \\
\hline crystallization & -261.93 & -261.58 & -260.7 & -1.92 \\
\hline melting & 285.45 & 287.12 & 288.06 & 2.28 \\
\hline
\end{tabular}

Our value of the melting temperature of $285.5 \mathrm{~K}$ fairly agrees with the range indicated by NIST [17] $(285 \pm 5 \mathrm{~K})$ or by reference [18] $(286 \mathrm{~K})$ but not with that recommended by the CRC Handbook $(288 \mathrm{~K})$ [19]. So does our value for the enthalpy of fusion $\left(2.28 \mathrm{~kJ} \mathrm{~mol}^{-1}\right)$ if compared with that reported by Acree and Chickos [20] $\left(2.41 \mathrm{~kJ} \mathrm{~mol}^{-1}\right)$. However these values are very far from that estimated by means of the method of Chickos et al. [21], i.e. $16.25 \mathrm{~kJ} \mathrm{~mol}^{-1}$. This discrepancy can be explained as follows: the estimation method yields the enthalpy change between the liquid state and the crystalline state corresponding to $0 \mathrm{~K}$, while the experimental value corresponds to a solid structure 
much more similar to that of the liquid. This explanation is consistent with the value of the enthalpy of sublimation reported by Bondi [22] at $166 \mathrm{~K}, 58.7 \mathrm{~kJ} \mathrm{~mol}^{-1}$.

An important overcooling effect, of over $23 \mathrm{~K}$ is observed. The crystallization enthalpy of the overcooled liquid corresponding to a nonequilibrium process is lower in absolute value than that of equilibrium melting.

\subsection{Determination of purity by DSC}

The Perkin Elmer Pyris DSC purity analysis software permits the assessment of purities for samples which undergo simultaneous degradation during melting. In Figure 2 is plotted the purity using Pyris software for cyclooctane. In the $T$ vs. $1 / \mathrm{F}_{\mathrm{S}}$ curve, the corrected data points are shown as black circles and the line drawn through them shows how the data fit the van't Hoff relationship Eq. (5). The black boxes represent the uncorrected values calculated for $1 / \mathrm{F}_{\mathrm{S}}$ (fraction melted) at given temperatures (Figure 3).

$$
1 / F_{S}=[\Delta H / R] \cdot\left[T_{0}-T_{S}\right] / T_{0}^{2} \cdot\left[1 / X_{2}\right]
$$

$T_{\mathrm{S}}$-sample temperature and the melting temperature, $\mathrm{K}$;

$T_{0}$-the melting temperature of the pure substance;

$\Delta H$-heat of melting of the pure material, $\mathrm{J} / \mathrm{g}$;

$X_{2}$-mole fraction of impurity in the sample;

$R$-constant $(8.314 \mathrm{~J} / \mathrm{mol} \mathrm{K})$;

$F_{\mathrm{S}}$-fraction of sample melting at temperature $T_{\mathrm{S}}$;

$F_{S}=A_{S} / A_{t}$

As-area of the melting endotherm up to temperature $T_{\mathrm{S}}$;

$\mathrm{A}_{\mathrm{t}}$-total area of melting endotherm

The DSC results indicated a higher purity $99.91 \pm 0.03 \%$ than the certified purity $>99 \%$ (GC) from Aldrich (CAS No. 292-64-8).

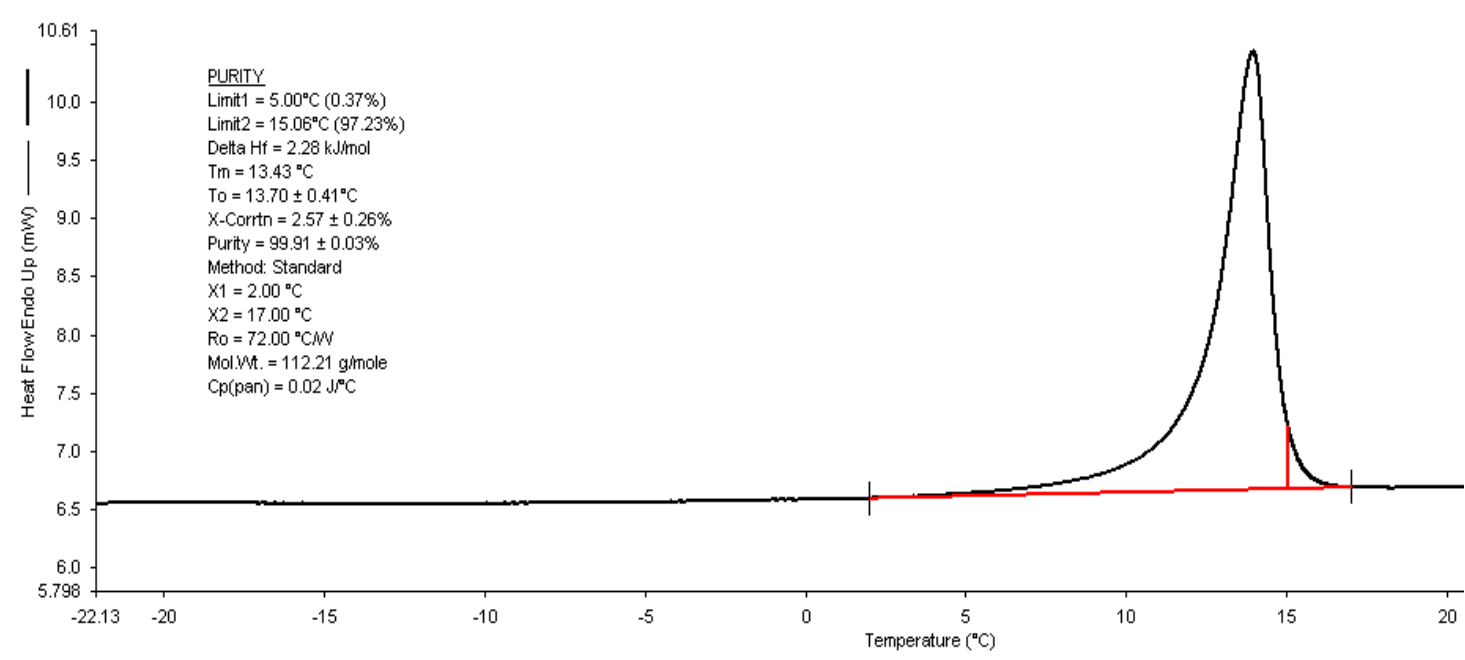

Figure 2. Determination of purity using Pyris software for cyclooctane 


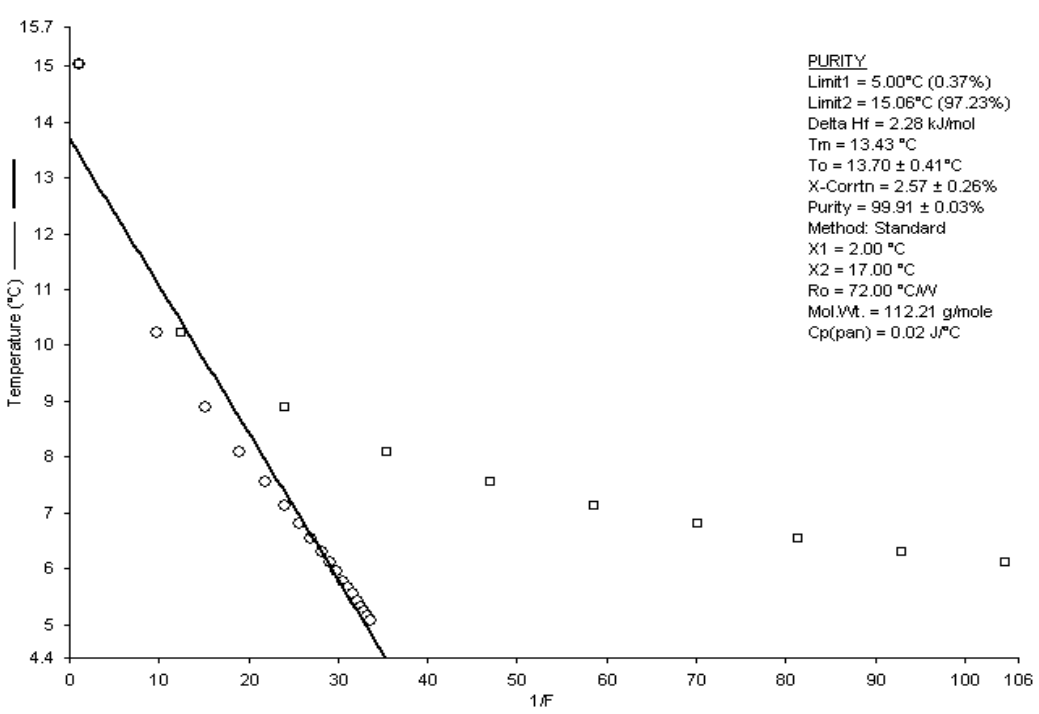

Figure 3. van't Hoff plot for cyclooctane

Our value of the enthalpy of formation in liquid state $\left(-156.2 \pm 1.2 \mathrm{~kJ} \mathrm{~mol}^{-1}\right)$ is less negative than literature data. This value corresponds to very large ring strain energy, of $49.6 \mathrm{~kJ} \mathrm{~mol}^{-1}$, if the group additivity scheme is used [16]. This value is closer to those of cyclononane and cyclodecane that to that of cycloheptane.

Different literature sources $[3,23]$ report for the standard enthalpy of vaporization values between 43.3 and $44.7 \mathrm{~kJ} \mathrm{~mol}^{-1}$. We obtain a value of $-112.8 \mathrm{~kJ} \mathrm{~mol}^{-1}$ for the ideal gas state enthalpy of formation, corresponding to a ring strain of over $52 \mathrm{~kJ} \mathrm{~mol}^{-1}$. Strain energies for cyclooctane ranging between 40 and $50 \mathrm{~kJ} \mathrm{~mol}^{-1}$ were reported in literature according to Zavitsas et al. [8] and of almost 60 $\mathrm{kJ} \mathrm{mol}^{-1}$ by Rogers et al. [26].

For the solid state enthalpy of formation of cyclooctane a value of $-182 \mathrm{~kJ} \mathrm{~mol}^{-1}$ was reported by Ruzieka and Schlapfer [5]. The calculated value in this state is $-235.28 \mathrm{~kJ} \mathrm{~mol}^{-1}[16]$ and $-238.4 \mathrm{~kJ} \mathrm{~mol}^{-}$ ${ }^{1}$ [24]. A ring strain of $55 \pm 3 \mathrm{~kJ} \mathrm{~mol}^{-1}$ is resulting from these data. The very low experimental value of the heat of fusion does not allow us to evaluate a ring strain in this state.

Most values of enthalpies of formation of eight membered ring cycloalkenes come from heats of hydrogenation and are based on the value of the enthalpy of formation of cyclooctane. In Table 5 are listed the experimental and calculated enthalpies of formation of such molecules, together with the corresponding strain energy.

The case of cyclooctene was more thoroughly investigated. The values of $\Delta_{\mathrm{f}} \mathrm{H}^{\mathrm{o}}$ of the cis isomer of this compound are calculated by means of heats of hydrogenation ranging between -96 and $-103 \mathrm{~kJ}$ $\mathrm{mol}^{-1}$. [25-28] The resulting strain of this molecule in liquid state $\left(32-39 \mathrm{~kJ} \mathrm{~mol}^{-1}\right)$ is to be compared with the gas phase values resulting from data of authors $[25,26,30]$ i.e. between 24 and $43 \mathrm{~kJ} \mathrm{~mol}^{-1}$. It is considered that cyclooctane contains considerable strain from van der Waals repulsion and unfavorable torsion, which is partly relieved in cis-cyclooctene. The much larger strain energy of trans-cyclooctene $\left(71-93 \mathrm{~kJ} \mathrm{~mol}^{-1}\right)$ is consistent with the instability of trans isomers of cycloalkenes with less than 10 atoms.

Table 5. Liquid phase enthalpies of hydrogenation and formation of 8-membered ring cycloalkenes and the corresponding strain energies

\begin{tabular}{|c|c|c|c|c|}
\hline Molecule & $\begin{array}{c}-\Delta_{\mathrm{h}} \mathrm{H}^{\mathrm{o}} / \\
\mathrm{kJ} \mathrm{mol}^{-1}\end{array}$ & $\begin{array}{l}\Delta_{\mathrm{f}} H^{\mathbf{o}}(\exp ) \\
/ \mathrm{kJ} \mathrm{mol}^{-1}\end{array}$ & $\begin{array}{c}\Delta_{\mathrm{f}} \mathrm{H}^{\mathrm{o}}(\text { calcd }) / \\
\mathrm{kJ} \mathrm{mol}^{-1} \\
{[16]}\end{array}$ & $\begin{array}{l}\text { Strain energy/ } \\
\mathbf{k J ~ m o l}^{-1}\end{array}$ \\
\hline cis-cyclooctene & $\begin{array}{c}102[25] \\
96.4[26] \\
103[27] \\
96.1[28]\end{array}$ & $-53--60$ & -92.28 & $32-39$ \\
\hline
\end{tabular}




\begin{tabular}{|c|c|c|c|c|}
\hline trans-cyclooctene & $\begin{array}{l}144[26] \\
135[28] \\
144[31] \\
\end{array}$ & $-12--21$ & -92.28 & $71-80$ \\
\hline $\begin{array}{c}\text { cyclooctene unspecified } \\
\text { stereoisomer }\end{array}$ & $94[29]$ & -62 & -92.28 & 30 \\
\hline 1,3-cyclooctadiene, $(Z, Z)$ - & $\begin{array}{c}204.8[31] \\
208[35]\end{array}$ & $49-52$ & 3.54 & $45-49$ \\
\hline 1,3-cyclooctadiene, (E,Z)- & $271[31]$ & 115 & 3.54 & 111 \\
\hline $\begin{array}{l}\text { 1,4-cyclooctadiene, unspecified } \\
\text { stereoisomer }\end{array}$ & $217.9[28]$ & 62 & 22.67 & 39 \\
\hline 1,5-cyclooctadiene, $(E, E)$ - & $320[31]$ & 164 & 21.28 & 143 \\
\hline 1,5-cyclooctadiene, (E,Z)- & $282[31]$ & 126 & 21.28 & 105 \\
\hline $\begin{array}{l}\text { 1,5-cyclooctadiene, unspecified } \\
\text { stereoisomer }\end{array}$ & $\begin{array}{c}230[31] \\
224.6[35]\end{array}$ & $69-74$ & 21.28 & $48-53$ \\
\hline 1,3,5-cyclooctatriene & $\begin{array}{l}319.6[35] \\
302.8[28]\end{array}$ & $146.5-163.5$ & 99.36 & $47-64$ \\
\hline 1,3,6-cyclooctatriene & $343.3[35]$ & 187 & 119.7 & 67 \\
\hline cyclooctatetraene & $409.9[28]$ & 254 & 177.44 & 75 \\
\hline
\end{tabular}

Although the most stable cyclooctadiene isomer is observed to be 1, 3-cyclooctadiene, (Z,Z)- a high value of strain energy is calculated for it. In fact this comes partially from a lack of conjugation of the two double bonds, conjugation taken into account in the calculated value. For 1,5-cyclooctadiene, three values of the enthalpy of formation based on heats of combustion were reported too [32-34]. The first two are assigned to the -ZZ stereoisomer, while for the last it is not specified. The last two values of $\Delta_{\mathrm{f}} H^{\mathrm{o}}, 18 \mathrm{~kJ} \mathrm{~mol}^{-1}$ [33] and $24 \mathrm{~kJ} \mathrm{~mol}^{-1}$ [34] would correspond to an improbable quasi-zero ring strain, while the value of authors [32] $\left(57.7 \mathrm{~kJ} \mathrm{~mol}^{-1}\right)$ is over $10 \mathrm{~kJ} \mathrm{~mol}^{-1}$ lower than the value obtained from heats of hydrogenation.

The isomer with conjugated structure is again the most stable in the case of cyclooctatrienes. It is observed that for samples of unspecified stereoisomers the enthalpy of hydrogenation has usually less negative values. This is probably due to a mixing effect.

An important value of the strain energy $\left(75 \mathrm{~kJ} \mathrm{~mol}^{-1}\right)$ is calculated for cyclooctatetraene. As in the case of the other conjugated molecules, the calculated value of $\Delta_{\mathrm{f}} H^{\mathrm{o}}$ includes a cconjugative stabilization contribution (group parameter $\left[\mathrm{C}_{\mathrm{d}^{-}} \mathrm{C}_{\mathrm{d}} \mathrm{H}\right]$ ) [16]. In fact in such a non-planar molecule such a contribution should be largely suppressed. [28, 35, 36] Two values of $\Delta_{\mathrm{f}} H^{\mathrm{o}}(1)$ obtained from heats of combustion are available $254.5 \mathrm{~kJ} \mathrm{~mol}^{-1}$ [37] and $248 \mathrm{~kJ} \mathrm{~mol}^{-1}$ [38]. The agreement between this first value and that calculated by us is excellent.

\section{Conclusions}

The ring strain energy of cyclooctane is quite large which explains the difficulty of synthesizing compounds with 8-membered rings.

The thermodynamic parameters of melting indicate that premelting processes occur at lower temperatures.

Acknowledgments: The authors gratefully acknowledge the Romanian Academy for financing the research program „Chemical Thermodynamics” of the „Ilie Murgulescu” Institute of Physical Chemistry. Support of the EU (ERDF) and Romanian Government, which allowed for the acquisition of the research infrastructure under POS-CCE O 2.2.1 Project INFRANANOCHEM-Nr. 19/01.03.2009, is also acknowledged. 


\section{References}

1.COX, J.D., PILCHER, G., Thermochemistry of Organic and Organometallic Compounds, Academic Press, New York, 1970, 1-636.

2.SPITZER, R., HUFFMAN, H.M., The heats of combustion of cyclopentane, cyclohexane, cycloheptane and cyclooctane, J. Am. Chem. Soc., 69, 1947, 211-213.

3. KAARSEMAKER, S., COOPS, J., Thermal quantities of some cycloparaffins. Part III. Results of measurements, Rec. Trav. Chim. Pays/Bas, 71, 1952, 261.

4.***Design Institute for Physical Properties Research (DIPPR), American Institute of Chemical Engineers, Project 801, 2006.

5.RUZIEKA, L., SCHLAPFER, P., Zurkenntnis des kohlenstoffringes XXII. Uber die verbrennungswarme bei hochgliedrigen ringverbindungen, Helv. Chim. Acta, 16, 1933, 162-169.

6. http://webbook.nist.gov/cgi/cbook.cgi?ID=C292648\&Mask=2\#ref-2

7. ZAVITSAS, A.A., ROGERS, D.W., MATSUNAGA, N., Heats of formation of organic compounds by a simple calculation, J. Org. Chem., 75, 2010, 6502-6515.

8. ZAVITSAS, A.A., MATSUNAGA, N., ROGERS, D.W., Enthalpies of Formation of Hydrocarbons by Hydrogen Atom Counting. Theoretical Implications, J. Phys. Chem. A, 112(25) 2008, 5734-5741.

9. WIESER, M.E., HOLDEN, N., COPLEN, T.B., BÖHLKE, J.K., BERGLUND, M., BRAND, W.A., DE BIE'VRE, P., GRÖNING, M., LOSS, R.D., MEIJA, J., HIRATA, T., PROHASKA, T., SCHOENBERG, R., O'CONNOR, G., WALCZYK, T., YONEDA, S., ZHU, X.K., Atomic weights of the elements 2011 (IUPAC Technical Report), Pure Appl. Chem. 85, 2013, 1047-1078.

10. GONZÁleZ, E.J., CALVAR, N., DOMINGUEZ, I., DOMÍNGUEZ, Á., (Liquid + liquid) equilibrium data for the ternary systems (cycloalkane + ethylbenzene +1 -ethyl-3 methylimidazolimethylsulfate) at $\mathrm{T}=298.15 \mathrm{~K}$ and atmospheric pressure, J. Chem. Thermodyn., 43, 2011, 725-730.

11. SPITERI, W.L., LETCHER, T.M., The excess enthalpies of cyclooctane $+n$-alkanes, Thermochim. Acta, 59, 1982, 73-80.

12. COOPS, J., JESSUP, R.S., VAN NES, K., Calibration of calorimeters for reactions in a bomb at constant volume, in: F.D. Rossini (Ed.), Experimental Thermochemistry, vol. 1, Interscience, New York, 1956, Chapter 3.

13. WASHBURN, E.W., Standard states for bomb calorimetry, J. Res. Natl. Bur. Stand., 10, 1933, 525-558.

14. OLOFSSON, G., Assignment of Uncertainties in: S. Sunner, M. Mansson, (Eds.), Combustion calorimetry, Pergamon Press, London, 1979, 137-159.

15. CODATA Bulletin nr. 28 (April 1978), Recommended Key Values for Thermodynamics, 1977, Paris, France.

16. DOMALSKI, E.S., HEARING, E.D., Estimation of the thermodynamic properties of C-H-N-O-SHalogen compounds at 298.15 K, J. Phys. Chem. Ref. Data, 22, 1993, 805-1160.

17. https://webbook.nist.gov/cgi/cbook.cgi? ID=C292648\&Mask=4.

18. MACKAY, D., SHIU, W.Y., MA, K.C., Volatile Organic Chemicals (Volume 3) in Illustrated Handbook of Physical-Chemical Properties and Environmental Fate for Organic Chemicals, 1993, (CRC Press) Lewis Publishers, 185.

19. LIDE, D.R., CRC Handbook of Chemistry and Physics, Internet Version, 2005, 3-142.

20. ACREE, W.E., CHICKOS, J.S., Phase Transition Enthalpy Measurements of Organic and Organometallic Compounds. Sublimation, Vaporization and Fusion Enthalpies From 1880 to 2015. Part 1. C1-C10, J. Phys. Chem. Ref. Data, 45, 2016, 033101. https://doi.org/10.1063/1.4948363

21. CHICKOS, J.S., ACREE, W.E., LIEBMAN, J.F., Estimating solid-Liquid Phase Change Enthalpies and Entropies, J. Phys. Chem. Ref. Data, 28(6) 1999, 1534-1673.

22. BONDI, A., Heat of Sublimation of Molecular Crystals: A Catalog of Molecular Structure Increments, J. Chem. Eng. Data, 8(3) 1963, 371-381. 
23. FINKE, H.L., SCOTT, D.W., GROSS, M.E., MESSERLY, J.F, WADDINGTON, G., Cycloheptane, cyclooctane, and 1,3,5-cycloheptatriene. Low-temperature thermal properties, vapor pressure, and derived chemical thermodynamic properties, J. Am. Chem. Soc., 78, 1956, 5469-5476.

24. SALMON, A., DALMAZZONE, D.J., Prediction of enthalpy of formation in the solid state at 298.15 K using second-order group contributions-part 2: carbon-hydrogen, carbon-hydrogen-oxygen, and carbon-hydrogen-nitrogen-oxygen compounds, J. Phys. Chem. Ref. Data, 36, 2007, 19-58.

25. DOERING, W.E., ROTH, W.R., BAUER, F., BREUCKMANN, R., EBBRECHT, T., HERBOLD, M., SCHMIDT, R., LENNARTZ, H.W., LENOIR, D., BOESE, R., Rotational barriers of strained olefines, Chem. Ber., 122, 1989, 1263-1266.

26. ROGERS, D.W., VON VOITHENBERG, H., ALLINGER, N.L., Heats of hydrogenation of the cis and trans isomers of cyclooctene, J. Org. Chem., 43, 1978, 360-361.

27. ROTH, W.R., LENNARTZ, H.W., Heats of hydrogenation. I. Determination of heats of hydrogenation with an isothermal titration calorimeter, Chem. Ber., 113, 1980, 1806-1817.

28. TURNER, R.B., MEADOR, W.R., Heats of hydrogenation. IV. Hydrogenation of some cis- and trans-cycloolefins, J. Am. Chem. Soc., 79, 1957, 4133-4136. TURNER, R.B., MEADOR, W. R. , DOERING, W. von E. , KNOX, L. H. , MAYER, J. R. , WILEY, D. W.W., Heats of Hydrogenation. III. Hydrogenation of Cycloöctatetraene and of Some Seven-membered Non-benzenoid Aromatic Compounds, J. Am. Chem. Soc., 79, 1957, 4127-4133.

29. ROGERS, D.W., MCLAFFERTY, F.J., A new hydrogen calorimeter. Heats of hydrogenation of allyl and vinyl unsaturation adjacent to a ring, Tetrahedron, 27, 1971, 3765-3775.

30. ROGERS, D.W., G2(MP2) calculation of the enthalpies of formation, isomerization and hydrogenation of cubane and cyclooctatetraene, J. Molec. Struct., 506, 2000, 207-215.

31. ROTH, W.R., ADAMCZAK, O., BREUCKMANN, R., LENNARTZ, H.W., BOESE, R., Die Berechnung von Resonanzenergien; das MM2ERW-Kraftfeld, Chem. Ber., 124, 1991, 2499-2521.

32.KOZINA,M.P., TIMOFEEVA,L.P., GAL'CHENKO,G.L., GVOZDEVA,E.A., CHEREDNICHEN

KO, V.M., The determination of the enthalphy of combustion of cis, cis-cyclooctadiene-1,5, Termodin. Org. Soedin., 1976, 9-11.

33. RAUH, H.J., GEYER, W., SCHMIDT, H., GEISELER, G., Bildungsenthalpien und mesomerieenergien von $\pi$-bindungssystemen, Z. Phys. Chem. (Leipzig), 253, 1973, 43-48.

34.LEBEDEV, B.V., TSVETKOVA, L.Ya., KIPARISOVA, E.G., LEBEDEV, N.K., Thermodynamic properties of cyclo-octa-1,5-diene, Russ. J. Phys. Chem. (Engl. Transl.), 49, 1975, 1265.

35. TURNER, R.B., MALLON, B.J., TICHY, M., DOERING, W.v.E., ROTH, W.R., SCHRODER,

G., Heats of hydrogenation. X. Conjugative interaction in cyclic dienes and trienes, J. Am. Chem. Soc.,

95, 1973, 8605-8610.

36. EDWARDS, K.F., PERIŞANU, St., LIEBMAN, J.F., The Aromaticity of Benzene and the Lack of Aromaticity of Cyclooctatetraene: Is Our Calorimetric Perspective a Manifestation of Convenience, Anthropocentrism, or Folksonomy, Int. J. Chem. Model, 5(1), 2013, 51-65.

37. PROSEN, E.J., JOHNSON, W.H., ROSSINI, F.D., Heat of combustion and formation of 1,3,5,7cyclooctatetraene and its heat of isomerization to styrene, J. Am. Chem. Soc., 69, 1947, 2068-2069; J. Am. Chem. Soc. 72, 1950, 626-629.

38. SPRINGALL, H.D., WHITE, T.R., CASS, R.C., Heats of combustion and molecular structure Part 1, The resonance energy and structure of cyclo-octateraene, Trans. Faraday Soc., 50, 1954, 815-819.

$\overline{\text { Manuscript received: } 18.09 .2019}$ 